\title{
Therapie bei aktinischer Keratose?
}

Betonen Ärzte bei einer aktinischen Keratose die Präkanzerose, überzeugen sie fast alle Patienten von einer Behandlung. Erläutern sie, dass die Läsionen nur selten entarten, will nur die Hälfte eine Therapie.

Wie Ärzte mit ihren Patienten kommunizieren, trägt viel zur Therapieentscheidung bei. So willigen Patienten am ehesten in eine Therapie bei aktinischer Keratose ein, wenn der Arzt diese als Krebsvorstufen darstellt. Betont er, dass die Läsionen weitgehend harmlos sind, ist der Anteil der Therapiebegeisterten deutlich geringer.

Zu dieser Erkenntnis gelangte ein Team um die Medizinstudentin Katherine Berry vom State College of Medicine in Hershey. Die Forscher hatten 228 Patienten einer dermatologischen Klinik sowie 311 Teilnehmern einer Online-Umfrage fünf verschiedene Statements zur aktinischen Keratose vorgelegt. Bei jedem sollten die Teilnehmer entscheiden, ob sie einer Therapie zustimmen würden. Sie lauteten:

1. Aktinische Keratosen sind durch Sonnenstrahlung verursachte Hautflecken. Etwa 0,5\% der aktinischen Keratosen entwickeln sich in lebensbedrohlichen Hautkrebs, $25 \%$ verschwinden wieder von selbst.

2. Aktinische Keratosen sind durch Sonnenstrahlung verursachte Hautflecken. Etwa 0,5\% der aktinischen Keratosen entwickeln sich in lebensbedrohlichen Hautkrebs, $75 \%$ verändern sich nicht.

3. Aktinische Keratosen sind durch Sonnenstrahlung verursachte Hautflecken. Etwa 99,5\% der aktinischen Keratosen entwickeln keinen Hautkrebs und $25 \%$ verschwinden von selbst.

4. Aktinische Keratosen sind durch Sonnenstrahlung verursachte Hautflecken. Etwa 99,5\% der aktinischen Keratosen entwickeln keinen Hautkrebs und $75 \%$ verändern sich nicht.

Thomas Müller,

springermedizin.de

5. Aktinische Keratosen sind Krebsvorstufen.
Wie zu erwarten, würden sich fast alle Teilnehmer (92\%) für eine Therapie entscheiden, wenn sie im Statement 5 nur erfahren, dass es sich bei den Läsionen um Krebsvorstufen handelt. Am geringsten war die Zustimmung beim dritten Statement mit 58\%.

Für Berry und Mitarbeiter erläutert das Beispiel, wie wichtig die Wortwahl der Ärzte und eine fundierte Diskussion über tatsächliche Risiken für die Therapieentscheidung sind. Darüber hinaus dürften die Ergebnisse der Umfrage für die dermatologische Praxis wenig relevant sein, da die meisten Teilnehmer nicht vor einer Therapieentscheidung standen. Zudem wurden allen Teilnehmern alle fünf Statements vorgelegt. Die ersten Statements haben jedoch mit hoher Wahrscheinlichkeit die Resultate für die folgenden beeinflusst.

hautnah $2017 \cdot 16: 44$

DOI 10.1007/s12326-017-0232-x

๑) Springer-Verlag Wien 2017

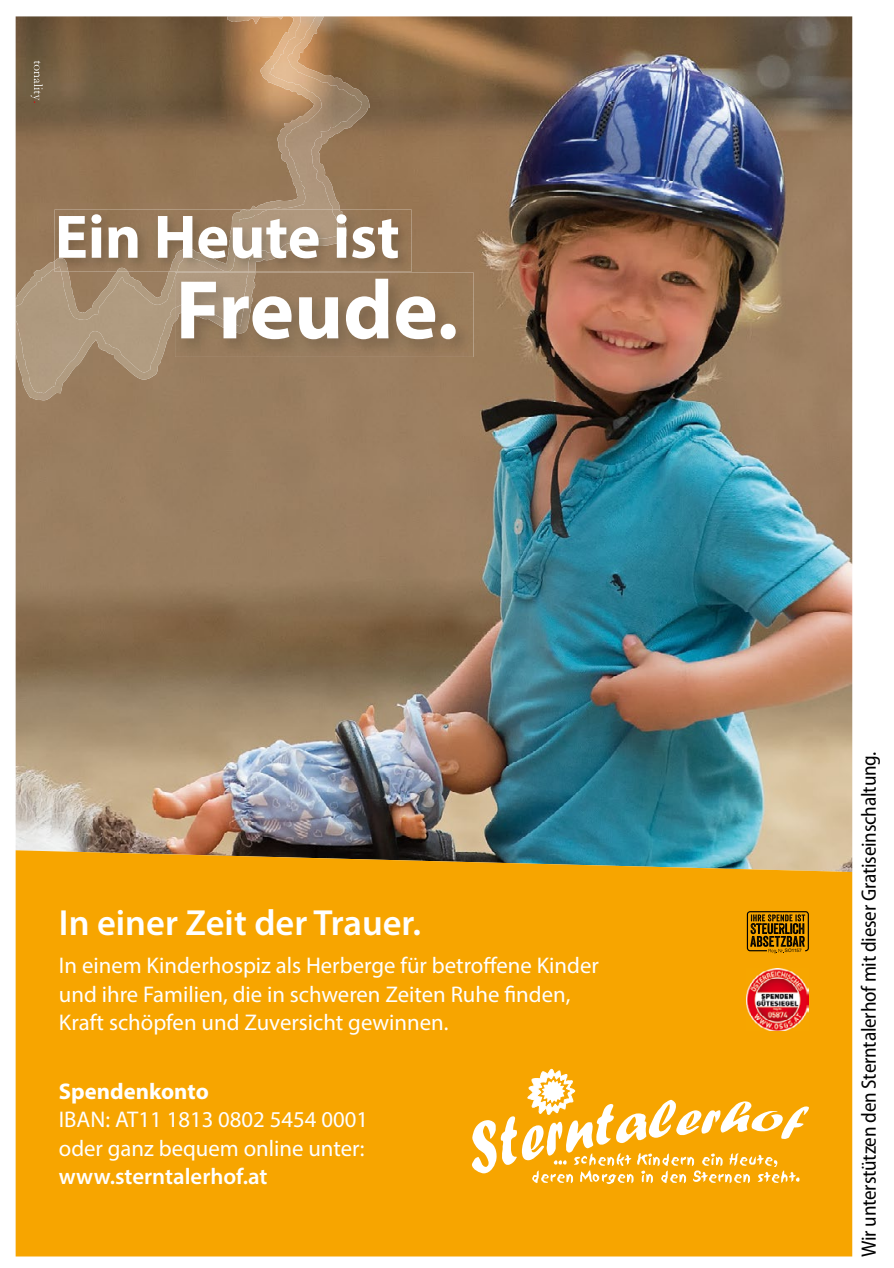

